\title{
Abordagem social na Ciência da Informação: do campo científico às práticas informacionais
}

Se por muito tempo pesquisadores e profissionais que se dedicaram à história dos registros da informação e do conhecimento centraram seus esforços na organização de espaços de custódia e memória, inclusive como forma de controle e censura, mais do que nunca direcionam suas atenções para questões relacionadas ao papel que a informação e o conhecimento desempenham no curso da humanidade. Nessa virada dos sabres e fazeres, o sujeito social passa a ser, em grande medida, uma das principais categorias analíticas que referenciam os diferentes processos de delimitação de campos, objetos, estudos, sujeitos e práticas informacionais.

Parte considerável da comunidade científica tem envidado esforços na ampliação e no aprofundamento da compreensão do sujeito em toda a dinâmica informacional. Nessa perspectiva, o presente número da Ciência da Informação em Revista traz um conjunto de seis artigos que abordam temáticas convergentes no contexto da informação, sendo um artigo original, três artigos de revisão e dois relatos de pesquisa.

No artigo original, "Do 'eu penso' da Ciência Moderna à consciência possível na Ciência da Informação: uma relação possível sob a égide da responsabilidade social da informação", o autor Luiz Eduardo Ferreira da Silva, partindo da caracterização do modelo científico moderno e do contexto que emerge a Ciência da Informação, busca compreender a responsabilidade social da informação com base na Ciência Moderna e na consciência possível por meio de regimes de informação. Considera que, em que pese o fato de a Ciência Moderna e a consciência possível se encontrarem separados cronológica e conceitualmente, encontrase um movimento convergente, principalmente, no que se refere aos usuários da informação e à relação social que esta desempenha no domínio da referida área de conhecimento.

No primeiro artigo de revisão, "Estudos de usuários: quais as diferenças entre os conceitos comportamento informacional e práticas informacionais?", os autores Flávia Virgínia Melo Pinto e Carlos Alberto Ávila Araújo problematizam os aspectos teórico-metodológicos que fundamentam os conceitos de "comportamento informacional" e "práticas informacionais", no domínio dos estudos de usuários. Adotando uma abordagem crítico-reflexiva, o artigo parte das origens dos estudos de usuários nos Estados Unidos da América e alcança as discussões contemporâneas no Brasil, destacando os modelos desenvolvidos por diferentes autores, nos cenários nacional e internacional. Consideram que as diversas abordagens dos estudos de usuários revisitadas evidenciam, a um só tempo, a relevância e a complexidade que envolvem a temática, sobretudo, por se tratar de fenômenos dinâmicos que constituem o convívio social. A partir dessas constatações, sugerem a ampliação de estudos que considerem a historicidade que envolve a construção e a atuação dos sujeitos informacionais, que já nascem e vivem em comunidade.

No segundo artigo de revisão, "Usabilidade e experiência do usuário de sistemas de informação: em busca de limites e relações", os autores Maria Aniolly Queiroz Maia, Ricardo Rodrigues Barbosa e Peter Williams realizam uma discussão acerca dos limites e das relações existentes entre a "usabilidade" e a "experiência do usuário", tomando como fundamento a literatura indexada nas bases de dados Scopus e Web of Science. Os autores constatam a 
carência de pesquisas capazes de unificar os significados desses conceitos e, consequentemente, promover o avanço e o aprofundamento de estudos nesse domínio temático. Consideram que, embora a usabilidade e a experiência do usuário contribuam para a melhoria das interfaces adotadas nos mais diversos equipamentos que têm como função organizar, recuperar e utilizar a informação, há na literatura uma série de características e a ausência de consenso que evidenciam a necessidade de aprofundamento com a realização de novas pesquisas.

No terceiro artigo de revisão, "Gestão de pessoas no contexto da Biblioteconomia/Ciência da Informação: revisão narrativa de literatura nos anais do CBBD e do SNBU", o autor Jorge Santa Anna, por intermédio de uma pesquisa descritiva e bibliográfica, analisa as comunicações apresentadas no Congresso Brasileiro de Biblioteconomia, Documentação e Ciência da Informação (CBBD) e Seminário Nacional de Bibliotecas Universitárias (SNBU), no período de 2012 a 2015, que abordam a gestão de pessoas no universo da instituição biblioteca. O autor constatou que há uma baixa produção da temática nos anais explorados, considerando que se referem a quatro edições dos dois principais eventos profissionais brasileiros na área de Biblioteconomia e Ciência da Informação. Por outro lado, embora de forma ainda tímida, a literatura estudada considera o capital humano como fator determinante para o bom desempenho das bibliotecas.

No primeiro relato de pesquisa, "Perspectivas da produção científica sobre epistemologia da Ciência da Informação no âmbito do ENANCIB", o autor Alexander William Azevedo analisa as comunicações sobre história e epistemologia da Ciência da Informação, realizadas em três edições do Encontro Nacional de Pesquisa em Ciência da Informação (ENANCIB), no período de 2014 a 2016. A partir de uma pesquisa exploratório-descritiva, o autor constata que há um processo de consolidação das pesquisas na área, considerando as temáticas abordadas, as autorias e as instituições que constituem as comunicações estudadas. No que se refere às temáticas, em particular, destacam-se aquelas relacionadas ao campo científico, à epistemologia e à história do campo, ao objeto de estudo e à interdisciplinaridade. Considera que os estudos sobre a epistemologia da Ciência da Informação pode ser realizado a partir de múltiplos enfoques.

No segundo relato de pesquisa, "Mediação em bibliotecas universitárias a partir dos eventos promovidos por essas instituições: um estudo no Estado do Ceará", a autora Izabel Lima dos Santos analisa os eventos promovidos pelas bibliotecas das universidades federais localizadas no Estado do Ceará como ambientes propícios para práticas mediacionais. Nesse sentido, explora a presença das bibliotecas em ambientes onlines como, por exemplo, blogs, Facebook, Instagram, Twitter, sites e You Tube. No segundo momento, mapeia os eventos que tiveram participações diretas ou indiretas das bibliotecas, com base nas seguintes categorias: recreativos, culturais, orientativos e outros. Considera que as bibliotecas das universidades federais cearenses realizam eventos, porém, ainda de maneira muito tímida. Assim, propõe que essas instituições ampliem a realização de eventos, buscando aperfeiçoar essas atividades mediacionais.

A Ciência da Informação em Revista agradece aos autores pela produção dos artigos e aos avaliadores pela análise e emissão dos respectivos pareceres. Deseja, enfim a todos, uma boa leitura.

\section{Edivanio Duarte de Souza}

Ronaldo Ferreira de Araujo

Editores 